\title{
Applying empirical learning progressions for a holistic approach to evidence-based education: SWANs/ABLES
}

\author{
Dr Emily White \\ Melbourne Graduate School of Education
}

https://doi.org/10.37517/978-1-74286-638-3_6

\begin{abstract}
Dr Emily White is a research fellow and sessional lecturer at the Melbourne Graduate School of Education, and a teacher practitioner with over 15 years' experience in inclusive and disability-specific education. Her research interests include accessible and valid assessment for students with disability, digital literacy, and understanding and supporting the learning of students with vision impairment using teacher expertise and evidence. She is currently working on an Australian Research Council Discovery Grant project exploring self-regulated learning in STEM classes. Emily lectures on using data to inform teaching for students with disability, and supporting access to learning via technology. Her PhD study investigated the development and validation of measures for assessing and teaching digital literacy for students with disability. Her assessment tool, derived empirical learning progression, and matched teaching strategies are now used in over 400 schools across Australia and abroad. At the Statewide Vision Resource Centre in Melbourne, she teaches and provides professional learning, having previously served in curriculum coordination, specialist, itinerant, and classroom roles across a range of settings.
\end{abstract}

\section{Abstract}

Learning progressions have become an increasing topic of interest for researchers, educational organisations and schools as they can describe the expected pathway of learning within a content area to allow for targeted teaching and learning at all levels of ability. However, there is substantial variation in how learning progressions are developed and to what extent teachers can use them to inform their practices. The ABLES/SWANs tools (Students with Additional Needs/Abilities Based Learning and Education Support) are an example of how an empirical learning progression can be applied to support teachers' ability to not only target teaching to a student's Zone of Proximal Development (Vygotsky, 1978), but also to plan, assess, and report on learning. Across Australia, these tools are used to help of thousands of teachers of students with disability to make evidencebased teaching and learning decisions and demonstrate the impact of their work with students. This approach, which scaffolds student achievement towards goals informed by an empirical learning progression, combined with reflective teaching practices, can help teachers to develop their capacity as professionals and provide the most effective teaching and learning for every student, regardless of the presence of disability or additional learning need.

\section{Introduction}

Learning progressions are gaining a substantial foothold in the minds of researchers and the practices of teachers. Global organisations such as the International Bureau of Education of the United Nations Educational, Scientific and Cultural Organization (UNESCO) have become increasingly interested in developing and applying learning progressions to support the learning of students around the world (Marope et al., 2019). On a national level, the Australian Council for Educational Research (ACER), the Australian Curriculum, Assessment, and Reporting Authority (ACARA), and the Assessment Research Centre at the Melbourne Graduate School of Education are all working on building learning progressions using different methodologies. 
While not all learning progressions are the same, they do follow the same premise: that the learning in a domain unfolds along a long-term developmental pathway, which can be described in increasing levels of difficulty and complexity (Heritage, 2008; Wiliam, 2007). This view contrasts with the notion that learning is simply the acquisition of age- or grade-level content to be taught. Rather, it positions the learner at the centre of a targeted teaching and learning process that addresses their current readiness to learn, in order to support the understanding of learning as a transformative process of increasingly sophisticated skill or understanding (White, 2019). By doing so, learning progressions 'represent not only how knowledge and understanding develops, but also predict how knowledge builds over time' (Stevens et al., 2002, p. 2). The provision of this critical information can support teachers to understand what a learner currently knows and can do in order for them to make good, evidence-based decisions about what a learner is ready to learn next and how best to support the learner towards that goal.

The idea that assessment might be 'as, for, and of' teaching has been strongly challenged by eminent scholars such as Patrick Griffin, who argue that assessment is solely for informing targeted teaching for every learner. The use of assessment to build a picture of a learner's current capabilities in a domain, as evidenced by what they can do, make, say or write, in conjunction with an empirical learning progression that describes the expected pathway of learning in that domain, can support the development of high-quality learning goals and planning to scaffold the learner along the pathway (Griffin, 2014). To understand the differences between empirical learning progressions and others, it is necessary to consider the methodology used to build a learning progression.

\section{Empirical learning progressions}

Empirical learning progressions refer to learning progressions developed using methodologies that incorporate data on student learning, as well as the knowledge of researchers and/or teachers. Not all methodologies for learning progressions use such an approach; some rely exclusively on the knowledge of researchers and/or teachers to describe a hypothesised learning progression in a domain such as numeracy or literacy. Whenever possible, the merging of an expertise basis with an evidence basis allows for the richest description of expected student learning in a domain, and can reflect the depth of knowledge held by expert teachers. For example, the outcomes of the Students with Additional Needs (SWANs)/Abilities Based Learning and Education Support (ABLES) project (SWANs/ABLES project) (University of Melbourne, 2017, 2018), which drew upon scholarly literature, teacher expertise, and student data to build empirical learning progressions for students with additional learning needs and/or disability, demonstrated that expert teachers were highly skilled at describing the likely learning pathways for these students. The close match found between their hypothesised rubric for a learning domain, and the rubric derived from student data, supported the notion that many expert teachers possess an accurate internalised learning progression created from many years of experience and high levels of training (see, for example, White, 2019; Woods, 2010).

The creation of an empirical learning progression requires substantial research and student data, and is thus more difficult and time-consuming to build than those built on a more hypothetical basis. As a result, many learning progressions are hypothetical in nature, though may still retain some strong arguments for validity. When considering a learning progression for use in schools, teachers should enquire about the methodological basis for the learning progression, and whether it was developed for the cohort of learners the teacher seeks to support. It is important that the span of capability described in a learning progression is inclusive of the range of domain-specific capabilities present in those learners; otherwise, the learning progression will not be valid for use with them. 


\section{Matching assessment with learning progressions}

Another important factor to consider when seeking to use a learning progression is whether it has a matched assessment. A matched assessment tool that has been found to be valid and reliable for a cohort of students can allow teachers to more accurately locate a student within a level described in a learning progression, and can serve as an indicator that a learning progression is empirically derived. Without a matched assessment tool, it can be more difficult to determine the most appropriate level for a student, as most learners will have a degree of ability in some aspects of a domain that belongs in a higher level, but are less skilled in other aspects of the domain. Having a matched assessment also allows teachers to use the same assessment at different time points to more reliably judge a learner's growth within the learning progression, so to reflect on which teaching practices and other influences have supported - or hindered - progress. Last, the results of the matched assessment can be used for reporting purposes, so to celebrate success with the learner and their family, to demonstrate the impact of specific learning interventions, and discuss what new or different approaches might be taken to further support learning.

\section{The SWANS/ABLES Project}

An example of an empirical approach to developing learning progressions derived from teacher expertise and student data can be found in the SWANs/ABLES project (University of Melbourne, 2017,2018 ) led by Patrick Griffin and Kerry Woods. This project created a holistic approach to assessment, planning, teaching, and reporting by using expert teacher knowledge to develop trial assessments that were used to collect data on the learning of thousands of students with disability and/or additional learning needs. The assessments were found to have strong arguments for their validity and reliability, so the data from them could be confidently used to build empirical learning progressions that described the likely trajectory of learning in nine foundational domains:

- literacy

- digital literacy

- numeracy

- communication

- social processes

- emotional understanding

- thinking skills

- learning skills

- movement.

Using teacher expertise and scholarly literature, teaching strategies were then developed to match each of the levels identified in each of the learning progressions, so to better support teachers to help learners progress from one level to the next. Lastly, multiple reporting formats were created to reflect a learner's location along the learning progression. Formats were devised for the purpose of reporting individual student ability and growth as well as class-wide and school-wide ability and growth over time as appropriate, both within and across domains. These formats allowed teachers and schools to celebrate student achievement with students and families based on evidence. They also allowed teachers and schools to reflect on differences in growth within an individual, and between groups of students, so to better understand the impact of planning and teaching decisions, resource provision, and external circumstances such as student absences. Today, hundreds of schools across Australia use SWANs or ABLES (a Victoria-specific version linked to the Victorian Curriculum) to support the achievement of students with disability and/or additional learning needs. 


\section{Assessment: Building a picture using evidence}

Returning to Griffin's (2014) assertion that assessment is for teaching, the complementary statement is that assessment is for understanding. When a teacher seeks to understand what a student knows or can do, another way to conceptualise this is to understand the amount of current capability a student possesses in a particular domain, or, the amount of a latent trait that the student has. As a latent trait is not directly measurable, in the way that height or speed are, it must be assessed using indirect measures, such as by determining what a student can do, make, say, or write (Griffin, 2014) as evidence of how much capability they have in a skill, knowledge, or behaviour within a domain. By collecting evidence of what a student can do, make, say, or write, teachers can assemble a rich understanding of how much current capability a student has in a domain, for the purpose of informing targeted planning for that student's learning. Evidence of current capabilities could include photos or videos of student learning behaviours, samples of student work, and statements a student makes in an interview, for example. These are all examples of observational assessment, as teachers are using their observations of a student to inform their understanding of student capability. By comparing a student's capabilities against a high-quality, preferably empirical, learning progression, teachers can then make decisions about what the student is likely to be ready to learn next, as the teacher can compare current student capability with descriptions of the same skill/knowledge/ behaviour at a more sophisticated or complex level.

As an example of using observational assessment to understand a student's current capabilities for the purpose of informing good planning and teaching, the SWANs/ABLES program allows teachers to use an online observational assessment tool to estimate a student's current location along the learning progressions for nine foundational learning domains. This program was developed to support teachers working with students identified as working below age- or grade-level for reasons of disability and/or additional learning needs. The observational assessment tool serves as a questionnaire version of a rubric that was developed using expert teacher knowledge, scholarly discourse, and student data, and found to have very strong arguments for reliability and multiple forms of validity. A teacher selects a learning domain, and, through a series of multiple-choice questions, draws upon their knowledge of the student to select the option for each question that best reflects what their student can do, make, say, or write on a typical day. The input from the teacher is then calculated using statistical analysis, and a description of the student's likely location on the learning progression is then displayed on a downloadable report, which also contains information about the levels above and below the student.

\section{Understanding a student's location on the learning progression}

A student's location on the learning progression can be understood as an estimate of their capability, as the true amount of a latent trait possessed by a student can never be fully understood or measured due to the indirectness with which it must be measured. On a more practical level for teachers, a student's capabilities will rarely be located entirely within one level, as it is expected that students possess different degrees of capability within the various skills, knowledges, and behaviours within a domain. So, while a student will be identified as generally working within a certain level though the assessment tool, teachers will often notice that a student is working at a slightly higher or lower level for some skills/knowledges/behaviours. As a result, teachers are encouraged to carefully read the student's identified level, as well as the levels above and below, in order to make the best decisions about what a student is ready to learn next - their Zone of Proximal Development (ZPD) (Vygotsky, 1978). By understanding each student's ZPD, teachers can begin to plan for individualised learning that supports students to meet learning goals based on what they are ready to learn next, rather than what an age- or grade-based curriculum says they should be taught next. 


\section{Setting targeted, evidence-based learning goals}

Once teachers have identified a student's current individual level of skills, knowledges, and behaviours within a domain's learning progression, the next step is to find descriptions of the same skills, knowledges, and behaviours at a higher degree of sophistication or complexity. It may be that some students who are identified as working within the middle of a level (so, they have achieved approximately half of the learning expected in that level) should then focus on consolidating the remainder of that learning, which can form the basis for their learning goals. Other students who might be at the very beginning or end of a learning progression level may instead need to focus on some of the learning within another level to support them to move more fully into the next level. Regardless of a student's current location, it is necessary that teachers can support their decisions about what the student should learn next through the accumulation of evidence that indicates their current capability. By considering how a student's current skill, knowledge, or behaviour is expressed in a more sophisticated or complex manner, as well as the student's priorities, teachers can then begin to make decisions about what learning goals might be the most important for the student, and about what a student is able to accomplish in a set amount of time (say, a school term or two).

\section{Planning for achievement: What works?}

Once a teacher has determined the student's learning goals within a domain, the next step is to identify how best to support that student to achieve them. While teachers who are highly experienced in a domain and in teaching will likely draw on their expertise to plan for individual student achievement, many teachers may wish to seek the advice and support of other more experienced teachers to assist in their planning. Using evidence-based practices from research literature are also likely to support student learning, though these can be difficult to locate due to time pressure on teachers and a lack of access to research journals.

One way that the SWANs/ABLES program (University of Melbourne, 2017, 2018) supported teachers was to provide a list of curated evidence-based teaching strategies and advice that was targeted at each level of each learning progression for the nine foundational areas. These strategies and advice were jointly developed from research findings of impactful practices and the knowledge of expert teachers before being trialled with classroom teachers who had a range of experience and expertise in the domain areas as well as in teaching students with disability and/or additional learning needs. As a result, a teacher using the SWANs/ABLES program (University of Melbourne, 2017,2018 ) to identify their student's current and next likely learning is also provided access to a range of targeted strategies and advice to support that student to reach their learning goals. While certainly not prescriptive, it can support teachers to not only recognise the good practices that they may already be implementing, as well as to suggest other new and different approaches. Teachers are encouraged to only apply strategies and advice that they perceive as relevant to their student, and to adapt strategies and advice as necessary to suit the individual needs or preferences of their students.

\section{Understanding impact: What worked?}

After a reasonable amount of time, such as a school term, a teacher should re-assess their student to determine the extent of learning against the goals that were set for that student. The same assessment procedures and tools used to determine the student's initial location on the learning progression should be used for subsequent assessments for reasons of reliability. These could be the same rubric or assessment tool, such as the SWANs/ABLES assessment tools (University 
of Melbourne, 2017, 2018), so that any demonstration of increasing capability by the student is recognised and acknowledged on the same scale that was used to determine their previous capability and to set their learning goals. Tracking student growth using the same metric allows for increased confidence in the result and fidelity in the teaching and learning cycle.

Once a student's learning growth has been assessed, it is important to consider the amount of growth as well as the possible reasons behind that amount of growth. Wherever possible, it can be helpful for teachers to have a clear representation of that growth, particularly when comparing growth across different domains. The SWANs/ABLES (University of Melbourne, 2017, 2018) individual reporting format uses a simple vertical arrow divided into sections to denote each level of a domain's learning progression, with thick black bars showing a student's estimated location on each assessment date. In this manner, teachers can quickly view growth between each time point in a domain. Another SWANs/ABLES (University of Melbourne, 2017, 2018) reporting format shows an individual's growth across multiple domains at each time of assessment, allowing for comparisons across domains, while other reporting formats allow students to be compared across a class or school, for the purpose of understanding general student abilities and to plan for different types of group learning.

When seeking to understand why a certain amount of growth has occurred, it is necessary to revisit the teaching strategies and advice used to inform the student's learning, as well as other factors such as resourcing, time, student absences, and other circumstances which may have positively or negatively affected learning. Teachers may wish to ask themselves, 'What evidence do I have that a particular intervention was successful - or not?'; 'Why did this student achieve so much in literacy, but relatively less in numeracy?'; 'What other aspects impacted their learning this term?'. Using these reflective teaching practices, supported by evidence, can help teachers to craft a better understanding of the student as a learner. They can also serve as the impetus for investigations, as appropriate, as to why a student may have achieved far more, or less, than expected in the time between assessments. Most importantly, they can help the teacher to craft increasingly effective teaching practices for each learner, so to support the success of every student.

\section{Building on success}

Teachers who incorporate high-quality learning progressions, such as those developed within SWANs/ABLES (University of Melbourne, 2017, 2018), into their practices can feel confident in providing an evidence-based, targeted learning experience for each student based on student capability, not age- or grade-level statements of what should be taught. The concept of the ZPD (Vygotsky, 1978) provides a strong basis for understanding student capability for the purpose of making good planning and teaching decisions for maximum growth. The use of evidence-based teaching strategies and advice to scaffold student achievement towards goals can mean that students make the most of their learning time, and meet high but reasonable expectations for their learning. Lastly, the implementation of reflective teaching practices to interrogate the reasons for student growth allows teachers to not only develop their own capacity as professionals, but to continue to provide the most effective teaching and learning for each student in their class. It is little wonder that organisations as large and respected as UNESCO see the implementation of learning progressions as central to the success of students worldwide; Australian students certainly deserve no less. 


\section{References}

Griffin, P. (2014). Assessment for teaching. Cambridge University Press.

Heritage, M. (2008). Learning progressions: Supporting instruction and formative assessment. http://www.ccsso.org/documents/2008/learning_progressions_supporting_2008.pdf

Marope, M., Griffin, P., \& Gallagher, C. (2019). Future competences and the future of curriculum: A global reference for curricula transformation. http://www.ibe.unesco.org/ sites/default/files/resources/future_competences_and_the_future_of_curriculum. pdf?fbclid=IwAR1Y3Ac0dNgpHqle02-OwYQ-b-eAZfwEHJ3PwnbUZa8TXIa-PZQpTrMjnhU

Stevens, S., Shin, N., Delgado, C., Krajcik, J., \& Pellegrino, J. (2002). Using learning progressions to inform curriculum, instruction and assessment design. [Paper presentation]. NARST Annual International Conference, New Orleans, LA, United States. http://hi-ce.org/presentations/ documents/Shawn_etal_NARST_07.pdf

University of Melbourne. (2017). Assessment and teaching of foundational skills for diverse learners: The Students with Additional Needs program. http://education.unimelb.edu.au/arc/projects/ current/assessment_and_teaching_of_foundational_skills_for_diverse_learners_the_students_ with_additional_needs_program\#about

University of Melbourne. (2018). Abilities Based Learning and Education Support (ABLES) research. https://education.unimelb.edu.au/research/projects/abilities-based-learning-and-educationsupport-ables-research

Vygotsky, L. S. (1978). Mind in society: The development of higher psychological processes (M. Cole, V. John-Steiner, S. Scribner, \& E. Souberman, Eds.). Harvard University Press.

White, E. H. (2019). Digital literacy for students with disability: Recognising ability and supporting learning through assessment, evidence, and expertise. [Doctoral dissertation, The University of Melbourne, Melbourne, Australia]. http://hdl.handle.net/11343/224996

Wiliam, D. (2007). Content then process: Teacher learning communities in the service of formative assessment. In D. B. Reeves (Ed.), Ahead of the curve: The power of assessment to transform teaching and learning. Solution Tree Press.

Woods, K. (2010). The design and validation of measures of communication and literacy to support the instruction of students with learning disabilities. [Doctoral thesis, University of Melbourne, Melbourne, Australia]. 